\title{
Transcription factor EGR3 is involved in the estrogen-signaling pathway in breast cancer cells
}

\author{
A Inoue ${ }^{1,2}$, Y Omoto', Y Yamaguchi', R Kiyama ${ }^{2,3}$ and S-I Hayashi1 \\ ${ }^{1}$ Division of Endocrinology, Saitama Cancer Center Research Institute, 818 Komuro, Ina-machi, Kitaadachi-gun, Saitama-ken 362-0806, Japan \\ ${ }^{2}$ Research Institute for Biological Resources and Functions, Tsukuba Center, National Institute of Advanced Industrial Science and Technology (AIST), \\ AIST Tsukuba Central 6, 1-1, Higashi 1-Chrome, Tsukuba-shi, Ibaraki-ken 305-8566, Japan \\ 3InfoGenes Co., Ltd., 1-1-1, Higashi, Tsukuba, Ibaraki-ken 305-8566, Japan
}

(Requests for offprints should be addressed to S-I Hayashi; Email: shin@ cancer-c.pref.saitama.jp)

\begin{abstract}
Estrogen has been closely associated with the genesis and malignant progression of breast cancer. However, the molecular mechanism underlying the effects of estrogen is far from being completely clarified. We previously developed a custom-made cDNA microarray consisting of approximately 200 estrogen-responsive genes in breast cancer cells. Using this system, we found one estrogen-induced gene in various cancer cell lines, including breast cancer MCF-7 cells, which encode a zinc-finger transcription factor, EGR3 (early growth response 3). Northern blot analysis of estradiol-treated MCF-7 cells showed rapid and robust induction of Egr3, and addition of cycloheximide or ICI 182,780 suggested that Egr3 is the bona fide target for the estrogen receptor $\alpha(E R \alpha)$. Using stable transformants derived from MCF-7 cells which were transfected with expression-controllable Egr3-expression vector, we demonstrated that Nab2 is one of the target genes for EGR3. Microarray analysis of the transformants revealed other candidate EGR3-induced genes. These strategies could be useful for analyzing downstream genes of $\mathrm{ER} \alpha$, and may contribute to elucidating the extensive signaling network of estrogen stimuli. Furthermore, a reporter assay using the upstream region of fas $L$ probably involving escape from the immune system revealed that fasL is another target gene for EGR3. The roles of EGR3 in the physiology of breast cancer are discussed.
\end{abstract}

Journal of Molecular Endocrinology (2004) 32, 649-661

\section{Introduction}

Estrogen plays an important role in the development of mammary glands and the genesis, growth and progression of breast cancer (Pike et al. 1993, Fanelli et al. 1996, Anderson et al. 1998). In normal and malignant mammary cells, estrogen receptor alpha $(\mathrm{ER} \alpha)$, one of the nuclear receptor transcription factors, is the primary target of estrogen, and the enhanced expression of ER $\alpha$ is one of the most frequent events in the development of breast cancer (Hayashi et al. 1997, Shoker et al. 1999).

There are many reports concerning the target genes transcriptionally activated by ER $\alpha$, such as pS2 (Masiakowski et al. 1982), cathepsin D (Westley \& Rochefort 1980) and Efp (Ikeda et al. 2000). Recently, gene-expression profiling of mammary tumors and breast cancer cells by microarray analysis has made an enormous contribution to expanding the list of novel estrogen-responsive genes (Finlin et al. 2001, Soulez \& Parker 2001, Bouras et al. 2002). At least some of those genes have been investigated regarding their function in breast cancer, and their significance in relation to the physiology of mammary tumors has been discussed (Finlin et al. 2001, Prest et al. 2002, Urano et al. 2002). Nonetheless, the entire mechanism of the pathway from ER $\alpha$ leading to the physiological effects on normal and malignant mammary cells is far from being completely clarified.

In a previous report, we developed a custommade cDNA microarray system consisting of approximately 200 estrogen-responsive genes (Inoue et al. 2002). Gene-expression profiling of human cancer cells with this microarray revealed that a gene encoding the zinc-finger transcription 
factor EGR3 (early growth response 3) was induced by estrogen in breast cancer MCF-7 cells and other cell lines derived from several other organs. Our novel findings concerning the estrogen-dependent expression of Egr3 suggest that EGR3 may play a key role in the estrogen-signaling pathway in a variety of organs, expanding the intracellular influence of estrogen through the transactivation of downstream target genes.

EGR3 belongs to the EGR family and shares a common sequence called the EGR response element with other members involved in DNAbinding and transactivation (O'Donovan et al. 1999). The activities of the members except for EGR4 are regulated by the specific cofactors NAB1 (Russo et al. 1995) and NAB2 (Svaren et al. 1996). EGR1, a prototype of the family, has been reported to be induced by diverse stimuli, including the addition of mitogens (Gashler \& Sukhatme 1995), and is considered to be involved in either cell proliferation or differentiation in a variety of tissues and cell lines. For example, EGR 1 was reported to be essential for the transcriptional autoregulation of basic fibroblast growth factor (bFGF) in hepatoma cells (Wang et al. 1997), and in the case of PC12 cells, EGR 1 was considered to be involved in differentiation induced by nerve growth factor (NGF), and the overexpression of cofactor NAB2 inhibited differentiation of the cells $(\mathrm{Qu}$ et al. 1998). EGR3 was also reported to be induced by various stimuli, a large number of which were the same as the case of EGR1 (O'Donovan et al. 1998, Mercier et al. 2001, Jouvert et al. 2002). Moreover, EGR3 has been shown to be essential for the development of muscle spindle in mice (Tourtellotte et al. 2001), and knockout mice (Egr3 -/-) exhibited several symptoms, such as gait ataxia and scoliosis, presumably due to the lack of muscle spindle (Tourtellotte \& Milbrandt 1998). On the other hand, fas $L$ has previously been reported to be induced under the control of EGR3 in $\mathrm{T}$ cells activated in a TGR-mediated manner or by phorbol ester plus a $\mathrm{Ca}^{2+}$ ionophore (Mittelstadt \& Ashwell 1998); fasL is the only target gene for EGR3 so far. In contrast, there has been no report regarding the expression and function of Egr3 in mammary gland and breast cancer. However, these findings regarding EGR3 led us to hypothesize that EGR3 may have an important role in the physiology of normal and malignant mammary cells, through being induced by estrogen and in turn inducing the expression of other estrogen-responsive genes, some of which were identified by our microarray analysis (Inoue et al. 2002).

This report addresses the role of $\operatorname{Egr} 3$ as an intracellular mediator of the estrogen-signaling pathway in breast cancer.

\section{Materials and methods}

\section{Cell culture}

Human breast cancer MCF-7 cells were maintained in RPMI 1640 medium (NISSUI Pharmaceutical, Tokyo, Japan) supplemented with 10\% fetal bovine serum (FBS) (Tissue Culture Biologicals, Tulare, CA, USA). For treatment of the cells with estrogen, the medium was replaced with phenol red-free RPMI 1640 medium (Sigma, St Louis, MO, USA) containing FBS treated with dextran-coated charcoal (DCG-FBS). All the culture media contained $2 \mathrm{mM}$ glutamine (Sigma) and $40 \mu \mathrm{g} / \mathrm{ml}$ gentamicin (Schering-Plough, Osaka, Japan). All cells were incubated at $37{ }^{\circ} \mathrm{C}$ in humidified air containing $5 \% \quad \mathrm{CO}_{2} . \quad \mathrm{MCF}-7$ Tet-Off cells (Clontech) and stable transformants derived from them were cultured as in the case of parental MCF-7 cells, except that $100 \mu \mathrm{g} / \mathrm{ml}$ of geneticin and $50 \mu \mathrm{g} / \mathrm{ml}$ of hygromycin (only for stable transformants) were added in each medium.

\section{Northern blot analysis}

For Northern blot analysis, MCF-7 cells were grown in estrogen-starved medium for 5-7 days and treated with ethanol $\left(\mathrm{E}_{2}{ }^{-}\right)$or $10 \mathrm{nM} 17 \beta$ estradiol $\left(\mathrm{E}_{2}{ }^{+}\right)$for the periods specified below. To examine the effects of estrogen antagonists, $1 \mu \mathrm{M}$ of 4-hydroxytamoxifen (Sigma) or ICI 182,780 (AstraZeneca Pharmaceuticals, Stanhope Gate, London, UK) was added to each medium together with $10 \mathrm{nM}$ of $17 \beta$-estradiol. Cycloheximide was added at the concentration of $10 \mu \mathrm{g} / \mathrm{ml}$ concurrently with ethanol or $17 \beta$-estradiol. Total RNA was prepared from each cell culture by the method of Chomczynski and Sacchi (1987). For each sample, $20 \mu \mathrm{g}$ total RNA were used for Northern analysis. DNA fragments (420-520 bp) for hybridization probes were prepared by RT-PCR, using total RNA from MCF-7 cells as a template and the following primers: 5'-CGA GGA TTA CGA ATG 
GGC C-3' and 5'-GCA GGC AAA GGG CTT CTC G-3' for Egr3 (Mages et al. 1993); 5'-AGG TCA GCG GCG ACA TCG-3' and 5'-CGG TGA AGG AGT TGG TGA C-3' for Egrl (Suggs et al. 1990); and 5'-ATG AAG GAG GCT GCT GCG-3' and 5'-CGT TCG TGG AAG TCT GCG-3' for $N a b 2$ (Kirsch et al. 1996). The primers for $p S 2$ and $\beta$-actin have been described previously (Inoue et al. 2002). RT-PGR, labeling of the probes and hybridization were performed as described previously (Inoue et al. 2002).

\section{Isolation of stable transformants with inducible Egr3 expression}

A $1.2 \mathrm{~kb}$ cDNA fragment containing the full-length coding region for Egr3 (Mages et al. 1993) was amplified by RT-PCR, using total RNA from MCF-7 cells as described above and the following primers: 5'-GGG GGATGG GAG TGG TAT GAC CGG CAA AG-3' and 5'-CGG GGATCG CGG ATG CTG AGG CGG AGG-3' (BamHI sites underlined). The Egr3 cDNA fragment was digested with BamHI and subcloned into the expression vector pTRE2hyg (Clontech) with the same orientation as that of the promoter. The resultant plasmid named pTRE2hyg:EGR3 and the empty vector pTRE2hyg were transfected into MCF-7 Tet-Off cells (Clontech), using Trans IT Polyamine Transfection Reagents (Takara, Tokyo, Japan) according to the manufacturer's instructions with some modifications. Briefly, MCF-7 Tet-Off cells were grown in the indicated media to $30-60 \%$ confluence. Each plasmid DNA was mixed with Trans IT LT-1 reagent in serum-free medium and added to the culture. After 2-day incubation, $100 \mu \mathrm{g} / \mathrm{ml}$ of hygromycin were added to the culture and incubated for about 2 weeks to select stable transformants. Single colonies were picked up and grown in the indicated media containing $100 \mu \mathrm{g} / \mathrm{ml}$ of geneticin and $50 \mu \mathrm{g} / \mathrm{ml}$ of hygromycin.

\section{Analysis of gene expression in stable transformants}

MCF-7 Tet-Off cells stably transfected with pTRE2hyg or pTRE2hyg:EGR3 were grown in the indicated media, to which $50 \mathrm{ng} / \mathrm{ml}$ of doxycycline were added. Afterwards, the media were changed and the culture was continued for $48 \mathrm{~h}$ in the presence or absence of $50 \mathrm{ng} / \mathrm{ml}$ of doxycycline. Isolation of total RNA and Northern blotting for several genes were performed as described above. For gene-expression profiling by EstrArray (InfoGenes Co., Tsukuba, Ibaraki, Japan), which is the improved version of the custommade microarray formerly named InfoArray (Inoue et al. 2002) (InfoGenes), stable transformants were grown in estrogen-starved medium for 2 days. The medium was then replaced, and the cells were treated with $100 \mathrm{ng} / \mathrm{ml}$ of doxycycline or $\mathrm{H}_{2} \mathrm{O}$ (control) for $72 \mathrm{~h}$. Poly (A) ${ }^{+}$RNA was isolated from the cells untreated and treated with doxycycline, and was used for preparation of Cy3- and Cy5labeled cDNA probes respectively. Labeling and hybridization of the cDNA probes into EstrArray were done according to the procedure described previously (Inoue et al. 2002) and the manufacturer's instructions. For comparison, the estrogenresponsive gene-expression pattern of parental MCF-7 cells was also analyzed by EstrArray, following the reported procedure (Inoue et al. 2002) and the manufacturer's instructions. Scanning and data analysis were performed as described previously (Inoue et al. 2002), except for the following modification. In the case of the stable transformants, the data for the spots with poor hybridization (signal areas of either Cy3 or Cy5 below 100) were removed from the data processing, to improve the correlation coefficients between duplicated sets of $\log _{2}(\mathrm{Cy} 3 / \mathrm{Cy} 5)$ values. In the case of parental MCF-7 cells, there was actually no need to cut off the data for improvement of the correlation coefficients $(0.968$ without filtration of the data).

\section{Luciferase reporter assay}

A $0.5 \mathrm{~kb}$ DNA fragment $(-347$ to +175 in base pairs from the transcription initiation site) containing the upstream region of fasL (Holtz-Heppelmann et al. 1998) was amplified with LA Taq polymerase (Takara), using the following primers: 5'-GCG GCTAGG GTT GTG TAT ATG GTA GAA TTC-3' (NheI site underlined) and 5'-CGG AAGGTT CTG GTG AGT CAG GCG AGC-3' (HindIII site underlined). The amplified DNA fragment was digested with NheI and HindIII and subcloned into a reporter vector pGL3-Basic (Promega, Madison, WI, USA). The resultant plasmid was named pGL3-FasL $0.5 \mathrm{~kb}$. For construction of the Egr3-expression plasmid, the expression vector $\mathrm{pRc} / \mathrm{CMV}$ (Invitrogen, Tokyo, 
A



B

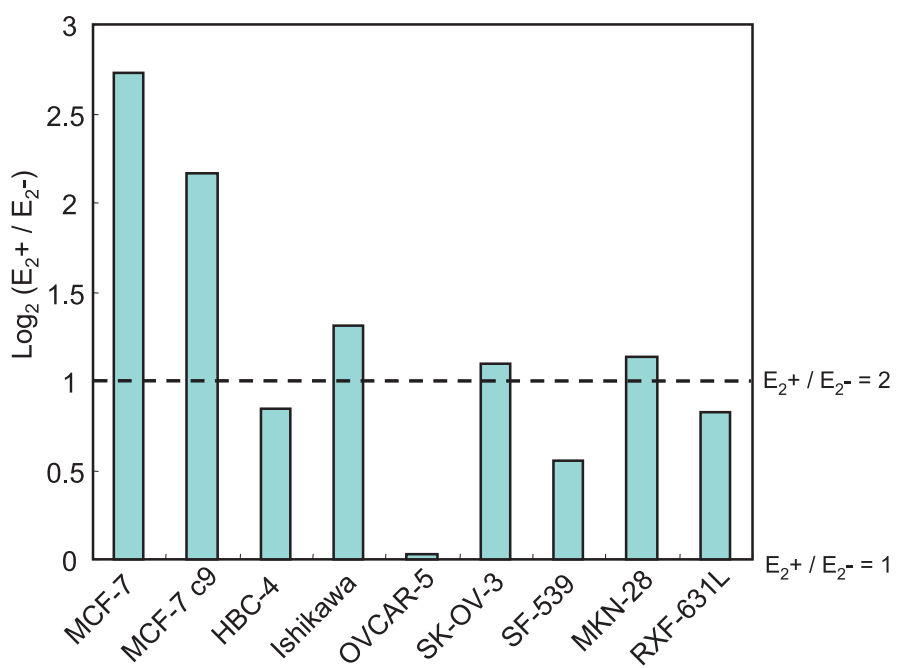

Japan) was digested with HindIII, polished with the Klenow Fragment, and 5'-dephosphorylated with alkaline phosphatase. The BamHI-digested 1-2-kb cDNA fragment encoding Egr3 described above was also polished with the Klenow Fragment and subcloned into $\mathrm{pRc} / \mathrm{GMV}$ with the same orientation as that of the promoter. The resultant plasmid was named pRc/CMV:EGR3. These plasmids were transiently transfected into MCF-7 cells cultured under estrogen-starved conditions for 2 days, using Trans IT Polyamine Transfection Reagents (Takara) as described above, together with an internal control vector pRL-TK (Promega). After incubation for $30 \mathrm{~h}$, the luciferase activity of each cell lysate was measured with the DualLuciferase Reporter Assay System (Promega), and each value was normalized to the internal Renilla luciferase activity as a control.

\section{Results}

\section{$\mathrm{E}_{2}$-responsive expression of Egr3 and related genes in MCF-7 cells}

Previously, we developed a custom-made cDNA microarray system consisting of approximately 200 estrogen-responsive genes (Inoue et al. 2002). Estrogen-responsive gene-expression profiling of human cancer cells using the microarray revealed that a gene encoding a zinc-finger transcription factor EGR3 was induced by $17 \beta$-estradiol treatment in breast cancer MCF-7 cells and several other cell lines derived from a variety of organs (Fig. 1), implying the significance of Egr3 as one of the key molecules in the estrogen-signaling pathway.

At first, we performed Northern blot analysis of Egr3 expression in breast cancer MCF-7 cells to 
confirm the results from microarray analyses and to investigate the time course of estrogenresponsive expression of the gene. As shown in Fig. 2, expression of Egr3 mRNA was induced $6 \mathrm{~h}$ after estrogen treatment, reaching a maximal induction level (10-20-fold) at 24-72 $\mathrm{h}$ after the treatment. This observation is similar to the expression patterns of the early-responsive estrogen-induced genes, such as $p S 2$ and insulinlike growth factor-binding protein 4 (IGFBP4), described in our previous report (Inoue et al. 2002).

The estrogen-responsive expression pattern of several genes related to Egr3 was also examined (Fig. 2). Egr1, the prototype of the EGR family, exhibited small fluctuations in the expression levels at each time point, but is not likely to be regulated by estrogen. Nab2, one of the cofactors specific for EGR family members, was induced by estrogen, as in the case of Egr3, but the start of substantial induction was apparently later than that of Egr3. On the other hand, another cofactor for EGR family members, Nab1, did not show estrogen-responsiveness (data not shown).

\section{Effects of antiestrogens and cycloheximide on $E_{2}$-responsive expression}

For further investigation, the effects of estrogen antagonists were analyzed. As shown in Fig. 3A, both the estrogen antagonists 4-hydroxytamoxifen (OHT) and ICI 182,780 severely inhibited Egr3 induction by estrogen. The extent of inhibition was much higher by ICI 182,780 than OHT. Similar observations were also obtained concerning the expression pattern of $\mathrm{Nab2}$. The effects of cycloheximide, a protein synthesis inhibitor, were also examined, and the results are shown in Fig. 3B. Egr3 exhibited a significant level of induction in response to estrogen even in the presence of cycloheximide, suggesting that the expression of Egr3 mRNA does not require de novo protein synthesis. These observations regarding Egr3 are similar to the case of $p S 2$, which has been demonstrated to be one of the primary targets for estrogen receptor $\alpha(\mathrm{ER} \alpha)$ (Brown et al. 1984, Stack et al. 1988). In contrast, Nab2 was not induced by estrogen in the presence of cycloheximide, suggesting that another de novo synthesized protein is at least in part essential for the expression of $\mathrm{Nab2}$.

\section{Identification of Nab2 as a downstream target gene for EGR3}

To investigate the function of Egr3, full-length Egr3 cDNA was cloned into the expression vector pTRE2hyg (Clontech) and stably transfected into MCF-7 Tet-Off cells (Clontech). The combination of pTRE2hyg with MCF-7 Tet-Off cells makes it possible to regulate transcriptionally a transfected gene by tetracycline or its analog doxycycline. Several isolated clones transfected with Egr3expression vector and one control clone transfected with empty vector were cultured in the presence or absence of doxycycline for 2 days, and Northern blot analysis of Egr3 expression was performed (Fig. 4). As expected, all the clones transfected with Egr3-expression vector demonstrated overexpression of Egr3 mRNA in the absence of doxycycline, and its addition drastically repressed Egr3 expression, whereas a control clone with empty vector showed no regulation of Egr3 expression. Moreover, Northern blot analysis revealed that the levels of $\mathrm{Nab2}$ mRNA were also under the control of doxycycline in Egr3-expressing transformants (Fig. 4). In all the Egr3-expressing clones examined, Nab2 was upregulated in the absence of doxycycline, that is, under the conditions allowing overexpression of Egr3. This suggests that Nab2 is one of the downstream target genes for EGR3.

\section{Microarray analysis using Egr3-expressing transformants}

To search for other target genes of EGR3 and investigate its contribution as a signal mediator in the estrogen signal network, we performed geneexpression profiling of Egr3-expressing transformants. For this purpose, we developed a microarray named EstrArray (InfoGenes), an updated version of the custom-made microarray previously reported (Inoue et al. 2002), replacing 28 genes in the former version with the same number of other clones which have been identified as estrogen-responsive genes through GeneChip analysis (Affymetrix) of MCF-7 cells (data not shown). Poly $(\mathrm{A})^{+}$RNA was isolated from the transformants cultured in the presence or absence of doxycycline, and the gene-expression patterns were analyzed with EstrArray (Fig. 5). Comparison of the gene-expression profiles of Egr3-expressing clones with estrogen-responsive gene-expression patterns in parental MCF-7 cells revealed candidate target genes of EGR3, which 
[EGR3]

Estradiol Treatment (10 $\mathrm{nM})$

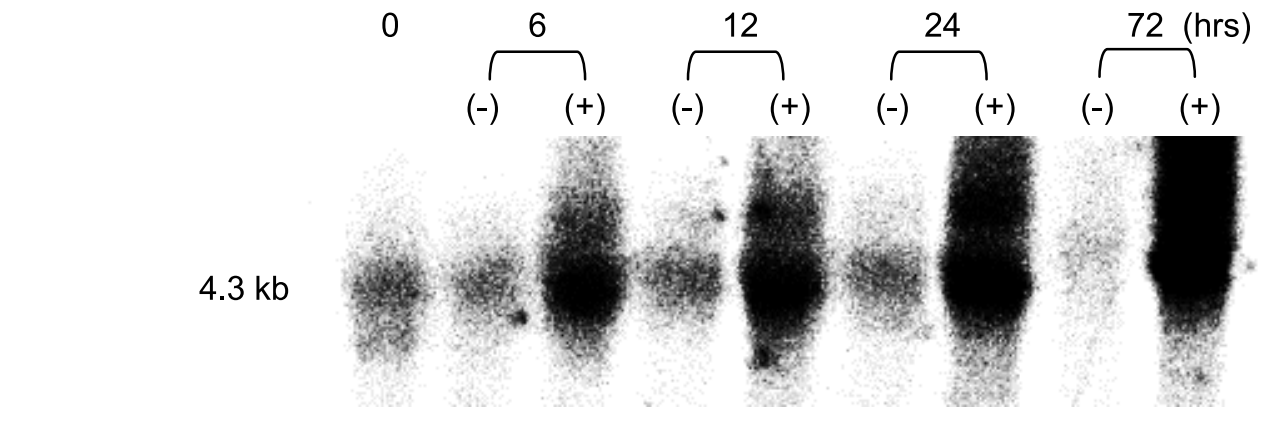

[NAB2]

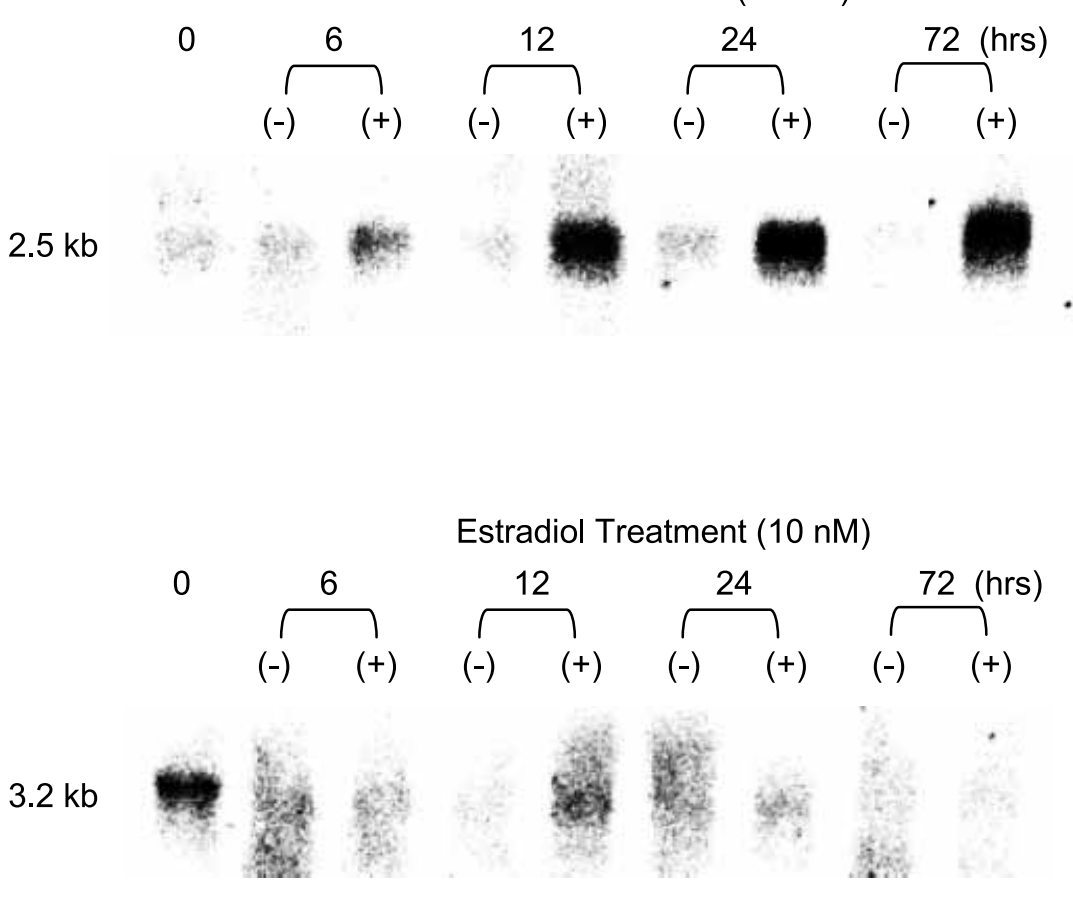

[EGR1]

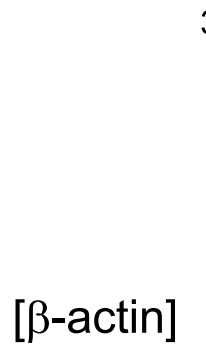

$1.8 \mathrm{~kb}$


Figure 2 Northern blot analysis of the expression of Egr3, Egr1 and Nab2.

Estrogen-starved MCF-7 cells were treated with 17 $\beta$-estradiol or ethanol for $6,12,24$, and $72 \mathrm{~h}$, and total RNA was isolated from each cell culture and from the cells without any treatment (shown as $0 \mathrm{~h}$ ). From each sample, $20 \mu \mathrm{g}$ total RNA were taken for Northern blot analysis, and cDNA fragments of the genes listed on the left were used as probes. The sizes of the transcripts are also shown on the left of the detected transcripts. Northern blot analysis of $\beta$-actin was also carried out as an internal control. 
A

$\begin{array}{lcccccc}\mathrm{E}_{2}(\mathrm{nM}) & - & 1 & 10 & 10 & 10 & \mathrm{CXM}(10 \mu \mathrm{g} / \mathrm{ml}) \\ \mathrm{OHT}(\mu \mathrm{M}) & - & - & - & 1 & - & \overbrace{\mathrm{E}_{2^{-}} \quad \mathrm{E}_{2}+(10 \mathrm{nM})}\end{array}$

EGR3

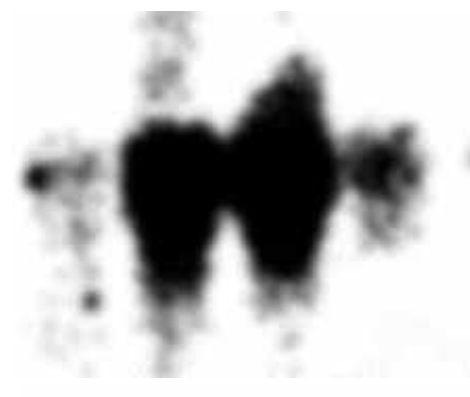

NAB2
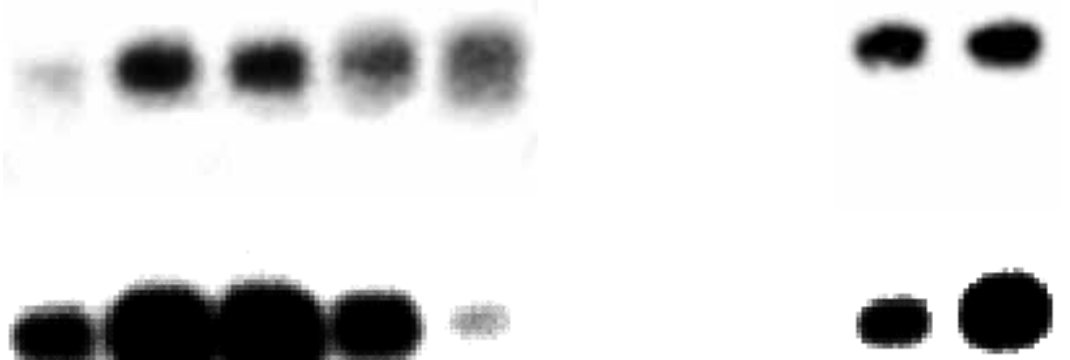

NAB2

pS2

(trefoil factor 1)
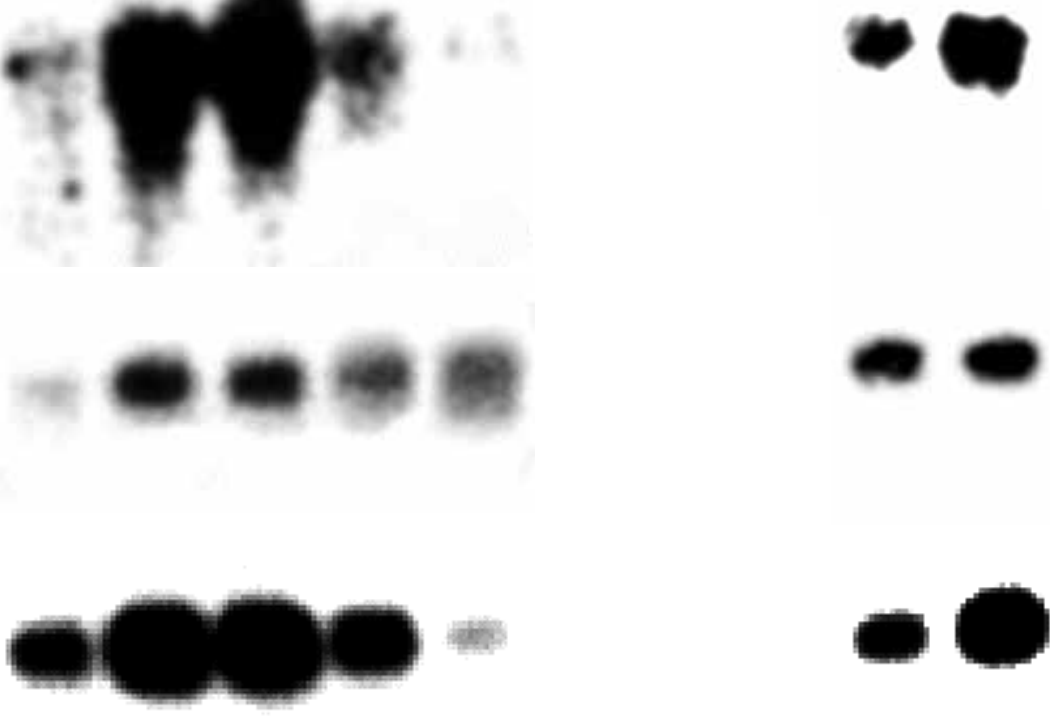

EGR3

NAB2

pS2
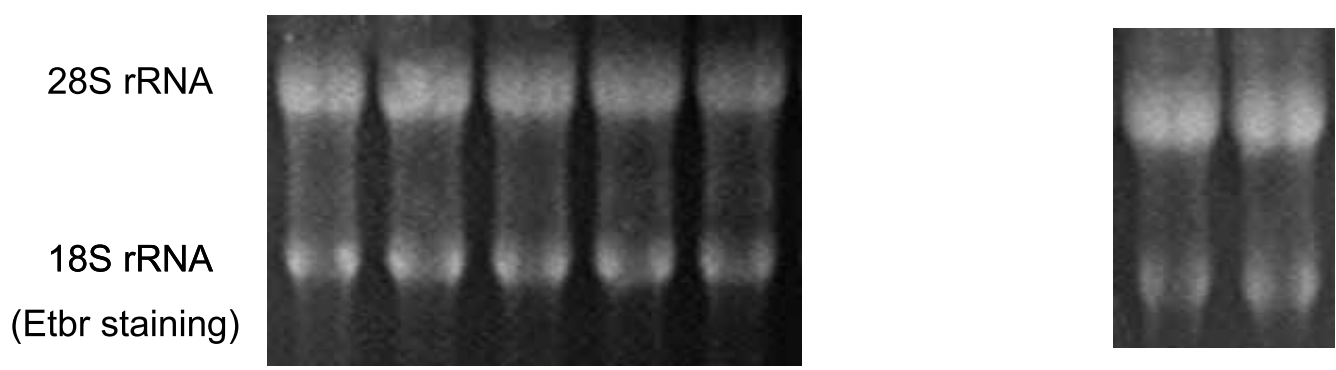

28S rRNA

18S rRNA

(Etbr staining)

Figure 3 Northern blot analysis to examine the effects of antiestrogens and cycloheximide. (A) MCF-7 cells grown in estrogen-starved culture were treated with $17 \beta$-estradiol $\left(E_{2}\right)$ alone, or $E_{2}$ and either 4-hydroxytamoxifen (OHT) or $\mathrm{ICl} 182,780$ at the indicated concentrations. After treatment for $72 \mathrm{~h}$, total RNA was isolated from the cells, and Northern blot analysis was performed for Egr3, Nab2 and pS2. (B) Estrogen-starved MCF-7 cells were treated with ethanol or $17 \beta$-estradiol together with cycloheximide (CXM) for $18 \mathrm{~h}$. Northern blot analysis was performed as for panel A. In both panels, gels stained with ethidium bromide (Etbr) are shown at the bottom.

was upregulated by estrogen in MCF-7 cells, and by the removal of doxycycline (by induction of $\operatorname{Egr} 3$ ) in one of the transformants (Fig. 5, cluster A and B). For example, a gene encoding TSC403 protein showed a $2 \cdot 5$-fold induction by estrogen in parental MCF-7 cells and 2-3-fold upregulation by removal of doxycycline in the clone Eg-11. One gene, which is suggested to be similar to chemokine receptor 2 , exhibited $1 \cdot 9$ - and $2 \cdot 1$-fold upregulation in parental and Eg-11 cells respectively. The proto-oncogene $c$-fos was induced $2 \cdot 5$-fold and $2 \cdot 1$-fold in parental and $\mathrm{Eg}-10$ cells respectively. These genes may be target genes induced by EGR3. On the other hand, in another clone, Eg-1, almost all the genes loaded 
EGR3

$\overbrace{+}^{\mathrm{Ctl}-7}+\overbrace{+}^{\mathrm{Eg}-1} \stackrel{\mathrm{Eg}-10}{\mathrm{Eg}-11} \stackrel{\mathrm{Eg}-13}{\overbrace{+}}$

NAB2

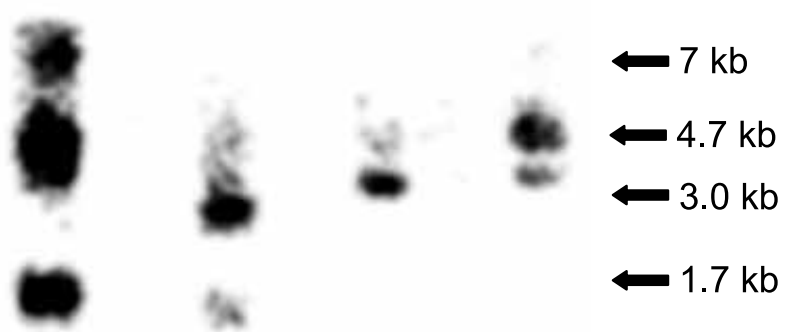

Dox

$\overbrace{+-}^{\mathrm{Ctl}-7} \overbrace{+}^{\mathrm{Eg}-1} \overbrace{+} \overbrace{+}^{\mathrm{Eg}-10} \overbrace{+}^{\mathrm{Eg}-11}$

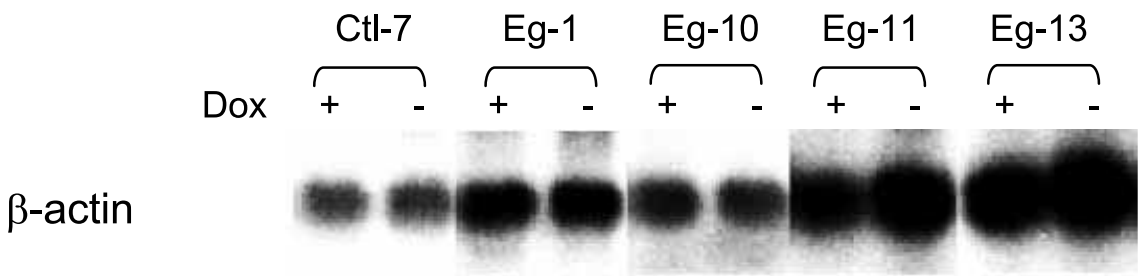

\section{S rRNA}

\section{$18 S$ rRNA \\ (Etbr staining)}

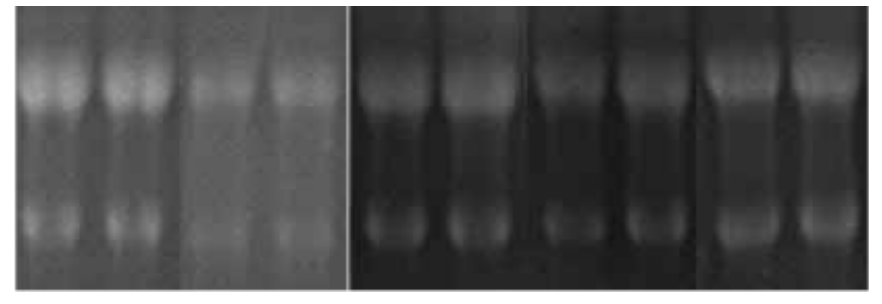

Figure 4 Northern blot analysis of Egr3 and Nab2 expression in stable transformants derived from MCF-7 cells. Transformants stably transfected with empty vector (Ctl-7) or Egr3-expression vector (Eg-1, -10, -11 and -13$)$ were grown for 2 days in the presence $\left(D^{+} x^{+}\right)$or absence $\left(D^{-} x^{-}\right)$ of $50 \mathrm{ng} / \mathrm{ml}$ doxycycline. Northern blot analysis for Egr3 and Nab2 was performed as in Figs 2 and 3. Northern blot analysis of $\beta$-actin was also carried out as an internal control. Gels stained with ethidium bromide (Etbr) are shown at the bottom. 


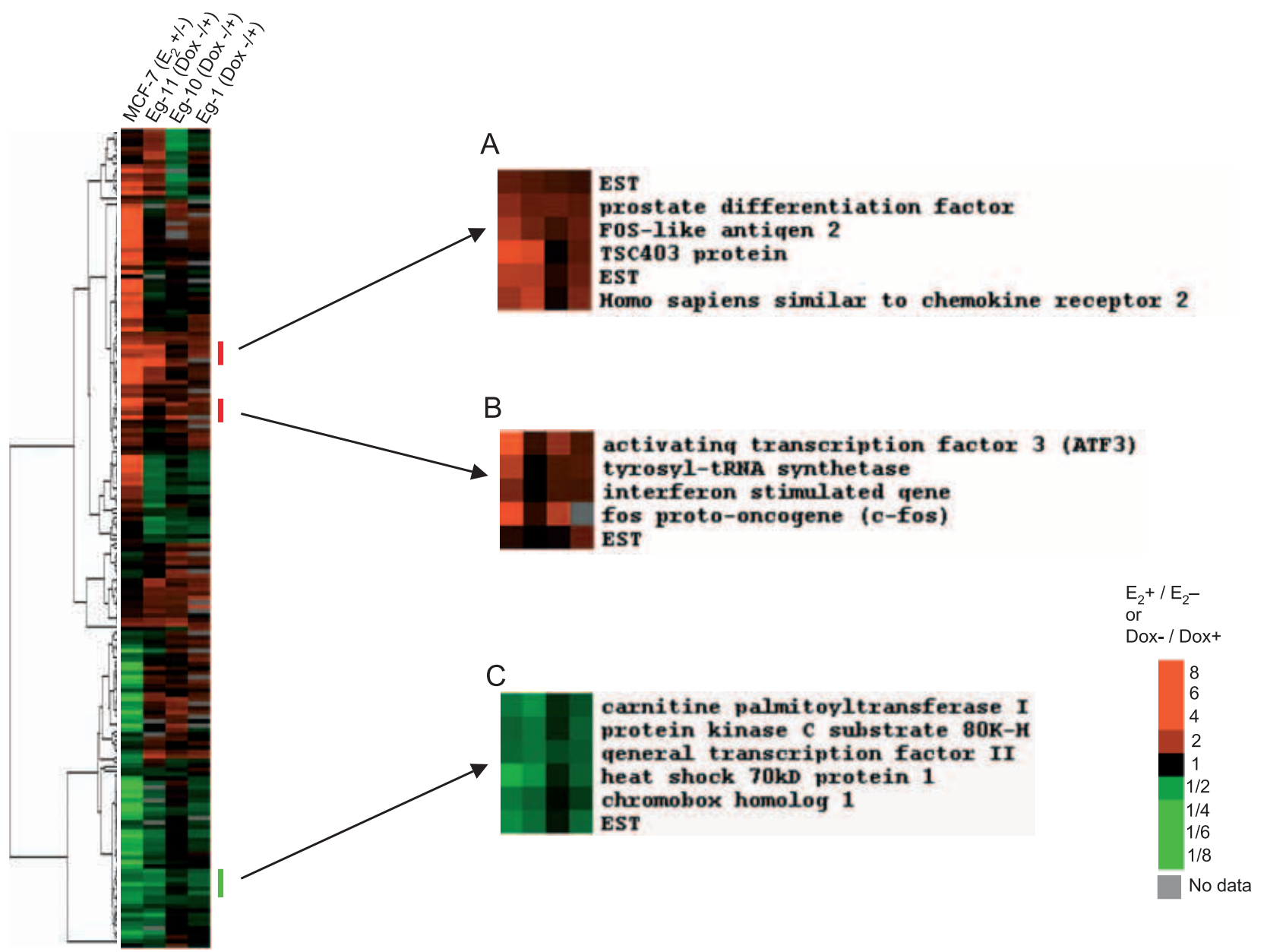

Figure 5 Gene-expression profiles of MCF-7 cells with EstrArray. Egr3-expressing Eg-1, -10 and -11 clones grown in estrogen-deprived media were cultured for $72 \mathrm{~h}$ in the presence (Dox+) or absence $\left(\right.$ Dox $\left.^{-}\right)$of $100 \mathrm{ng} / \mathrm{ml}^{\prime}$ doxycycline, and poly $(A)^{+}$RNA was isolated from the cells. Hybridization into EstrArray was performed as described previously (Inoue et al. 2002) and according to the manufacturer's instructions. Estrogen-responsive

gene-expression profiling of parental MCF-7 cells was also performed with EstrArray, and the results are shown for comparison. After filtrating of the data of expression ratios, as described previously (Inoue et al. 2002), 186 genes for which there were remaining data in at least three cell lines were selected from the total of the genes loaded on EstrArray, and analyzed by hierarchic clustering. The results are represented as a pseudocolor visualization matrix. The characters of gene clusters denoted by the bars and letters $A$ to $C$ are as follows: $(A)$ a group containing the genes whose differential expression ratios are nearly or more than $2 \cdot 0$, both in parental MCF-7 cells and clone Eg-11; (B) a group containing a gene (c-fos) whose differential expression ratio is equal to or more than $2 \cdot 0$, both in parental MCF-7 cells and clone Eg-10; (C) a group including the genes repressed by estrogen and removal of doxycycline in parental MCF-7 cells and clone Eg-11 respectively. All the gene groups are zoomed, and the expression patterns with gene names are shown on the right. The color scale used to represent the expression ratios is shown on the lower right. The gray color means that there are no reliable data after filtrating due to poor hybridization.

on EstrArray showed no significant induction by removal of doxycycline. Among the estrogenrepressed genes, some genes had similar expression patterns between parental MCF-7 cells and Eg-11 cells (Cluster $\mathrm{C}$ ), but the rationale of repression of these genes by EGR3 is unknown.

\section{Promoter of fasL was activated by EGR3 in breast cancer cells}

The fas $L$ gene is the only gene so far identified as a target of EGR3. It was demonstrated that, in activated $\mathrm{T}$ cells, induction of fas $L$ mRNA is 




$(1 \mu \mathrm{g})$

Figure 6 Luciferase reporter assay for the activity of fas $L$ promoter. Luciferase reporter plasmid harboring a $0.5 \mathrm{~kb}$ fragment upstream of fas $L$ was transfected into estrogen-starved MCF-7 cells together with the Egr3-expression vector at the indicated dosage. A reporter plasmid without the promoter fragment (pGL3-basic) and empty expression vector ( $\mathrm{pRc} / \mathrm{CMV}$ ) were also used for controls. After incubation for $30 \mathrm{~h}$, the luciferase activity of the cell lysate was measured and normalized to the internal control luciferase activity. The results are shown as the average \pm standard deviation $(n=3)$ of relative luciferase activity where that of the cells transfected with $25 \mathrm{ng} \mathrm{pRc/CMV}$ and $1 \mu \mathrm{g}$ pGL3-FasL $0.5 \mathrm{~kb}$ was taken as $100 \%$.

mediated by EGR3, and the 16-mer sequence called Fas ligand regulatory element (FLRE) in the promoter region is sufficient for fas $L$ expression induced by EGR3 (Mittelstadt \& Ashwell 1998). It was also reported that a reporter plasmid bearing the 16-mer FLRE was also transactivated by ectopically expressed EGR3 in nonlymphoid HeLa cells (Mittelstadt \& Ashwell 1998), implying that the regulation of fas $L$ expression by EGR 3 may be a common pathway existing not only in lymphoid cells but also in other tissues. We at first tried to examine the expression levels of fas $L$ mRNA in Egr3-expressing transformants and parental MCF-7 cells. However, quantitative analysis was impossible, while fas $L$ mRNA could faintly be detected in parental MCF-7 cells (data not shown), presumably because of too low expression levels or instability of fas $L$ mRNA. EstrArray is also unavailable for analysis of fas $L$ because fas $L$ cDNA is not loaded on it. Therefore, we examined the fas $L$ expression using a reporter assay. Luciferase reporter vector harboring a $0 \cdot 5 \mathrm{~kb}$ upstream region of the fas $L$ gene containing FLRE was transiently transfected into MCF-7 cells together with Egr3 expression vector containing a constitutive CMV promoter upstream of $E g r 3$, and the activity of the fas $L$ promoter was examined. As shown in Fig. 6, overexpression of Egr3 increased fasL promoter activity approximately twofold compared with the case without ectopic expression of Egr3. This observation suggests that fas $L$ may be another target gene for EGR3 in breast cancer as well as in T cells. 


\section{Discussion}

In this study, we focused on the functional analysis of Egr3 encoding a zinc-finger transcription factor in breast cancer cells. We have previously identified Egr3 as one of the estrogen-responsive genes that was induced in breast cancer MCF-7 cells after estrogen treatment for $72 \mathrm{~h}$. Estrogen-dependent induction of this gene was also observed in cell lines derived from various other tissues. Northern blot analysis in this study revealed that Egr3 was induced by estrogen at the early phase (at the latest within $6 \mathrm{~h}$ after estradiol treatment) independently of de novo protein synthesis, and antiestrogens blocked the inducible expression of Egr3. These observations strongly suggest that Egr3 is one of the primary targets for the ER. There are at least three EREs (estrogen-responsive elements) upstream of $\operatorname{Egr3}$ ( -2843 to $-2839,-2701$ to -2697 and -693 to $-689 \mathrm{bp}$ from the transcriptional initiation site) to which the ER would bind, leading to transactivation. However, it is unknown and requires further investigation whether these elements are responsible for ER-mediated transactivation of the gene.

Northern blot analysis of Nab2 in Egr3overexpressing stable transformants suggested that Nab2 is one of the downstream target genes for EGR3. This conclusion is consistent with the results from Northern blot analysis using parental MCF-7 cells, in which $\mathcal{N a b 2}$ was also induced by estrogen, but this was dependent on de novo protein synthesis. NAB2 was at first identified as a corepressor for EGR1 (Svaren et al. 1996), but in some cases it was demonstrated to work as a coactivator for EGR3-mediated transactivation (Sevetson et al. 2000). NAB2 is considered to exert either positive or negative effects on the transactivation of target genes for EGR3, depending on the promoter construction of the genes. In either case, it is reasonable to assume that estrogen-induced EGR3 in turn enhances the expression of NAB2, an effect which may have feedback effects on expression patterns of EGR3-induced genes at a later phase in breast cancer cells exposed to estrogen.

Gene-expression profiling in Egr3-expressing clones using EstrArray found other candidate target genes induced by EGR3. Among them, the TSC403 gene has been reported to encode protein similar to lysosomal membrane glycoproteins (lamps) 1 and 2, and demonstrated to be overexpressed only in malignant cells, but not normal cells, in several tissues such as the breast and colon (Ozaki et al. 1998). TSC403 may be involved in the genesis and/or progression of breast tumors. The proto-oncogene c-fos encoding a transcription factor has been demonstrated to be induced by estrogen at an early phase in MCF-7 cells (Duan et al. 1999). This gene is considered to be one of the primary targets for ER, but another pathway might exist for transactivation of $c-f o s$ at a late phase mediated by EGR3. It is unknown why different gene-expression patterns were observed in the three transformants, although regulation of Egr3 expression by doxycycline was prominent in all the clones (Fig. 4). It is possible that the expression patterns of target genes for EGR3 may be influenced not only by the amounts of EGR3 proteins but also by the relative amounts of cofactor NAB2 induced by EGR3, because there were quite different $\mathcal{N a b 2}$ expression levels in these clones.

On the other hand, fasL is the only target gene for EGR3 so far identified. A limited region upstream of the fas $L$ gene has been demonstrated to be sufficient for EGR3-mediated transactivation, both in T cells and nonlymphoid HeLa cells, a fact which prompted us to test whether the fasL promoter could also be activated by EGR3 in breast cancer cells. The luciferase reporter assay suggested that fas $L$ is another target gene for EGR3 in breast cancer. There are several reports concerning the expression of Fas ligands in tumors derived from several organs such as the breast (Gutierrez et al. 1999) and ovary (Rabinowich et al. 1998). FasL expression in these malignant cells is considered to be one of the mechanisms involved in escape from immune surveillance, leading encountered $\mathrm{T}$ cells into apoptosis, and it would bring about an advantage in the progress and metastasis of the tumor cells in vivo. Considering these facts, it can be hypothesized that EGR3 has an important role in the estrogen-dependent induction of the immune evasion system in ER-positive breast cancer, although further study will be needed to demonstrate this attractive hypothesis.

In conclusion, we believe that identification of Egr3 as one of the ER-mediated estrogen-induced genes sheds light on a novel estrogen-signaling pathway in breast cancer cells. We hypothesize the scheme and role of the novel estrogen-signaling pathway as shown in Fig. 7. In this pathway, 




Figure 7 Hypothetical schema of EGR3-mediated estrogen-signaling pathway in MCF-7 cells.

estrogen and ER induce the expression of Egr3, and EGR3 protein in turn induces a specific cofactor, NAB2. EGR3 also induces other genes such as the TSC403 gene and fasL, with its activity being modulated by NAB2. Considering previous reports on them, these gene products may have no effect on the growth of breast cancer. However, these proteins may play their own roles in conferring superiority in the progression and metastasis of breast tumors which have emerged in vivo.

\section{Acknowledgements}

We thank Ms Akiyo Yamashita for her excellent technical assistance. This study was supported in part by grants-in-aid from the Ministry of Education, Culture, Sports, Science and Technology of Japan for Cancer Research; from the Ministry of Health, Labor and Welfare of Japan for Scientific Research Expenses for Health and Welfare Programs and the Foundation for the Promotion of Cancer Research and for the Second-Term Comprehensive 10-Year Strategy for Cancer Control; from the Ministry of the Environment of Japan for the Pollution Control
Technology; and from the Ministry of Economy, Trade and Industry of Japan for Research Projects for Smaller Enterprises.

\section{References}

Anderson E, Clarke RB \& Howell A 1998 Estrogen responsiveness and control of normal human breast proliferation. Fournal of Mammary Gland Biology and Neoplasia 3 23-35.

Bouras T, Southey MC, Chang AC, Reddel RR, Willhite D, Glynne R, Henderson MA, Armes JE \& Venter DJ 2002 Stanniocalcin 2 is an estrogen-responsive gene coexpressed with the estrogen receptor in human breast cancer. Cancer Research 62 1289-1295.

Brown AM, Jeltsch JM, Roberts M \& Chambon P 1984 Activation of pS2 gene transcription is a primary response to estrogen in the human breast cancer cell line MCF-7. PNAS 81 $6344-6348$

Chomczynski P \& Sacchi N 1987 Single-step method of RNA isolation by acid guanidinium thiocyanate-phenol-chloroform extraction. Analytical Biochemistry 162 156-159.

Duan R, Porter W, Samudio I, Vyhlidal C, Kladde M \& Safe S 1999 Transcriptional activation of c-fos protooncogene by 17 beta-estradiol: mechanism of aryl hydrocarbon receptor-mediated inhibition. Molecular Endocrinology 13 1511-1521.

Fanelli MA, Vargas-Roig LM, Gago FE, Tello O, Lucero De Angelis R \& Ciocca DR 1996 Estrogen receptors, progesterone receptors, and cell proliferation in human breast cancer. Breast Cancer Research and Treatment 37 217-228.

Finlin BS, Gau C-L, Murphy GA, Shao H, Kimel T, Seitz RS, Chiu Y-F, Botstein D, Brown PO, Der CJ, Tamanoi F, Andres DA \& Perou CM 2001 RERG is a novel ras-related, estrogen-regulated 
and growth-inhibitory gene in breast cancer. Fournal of Biological Chemistry 276 42259-42267.

Gashler A \& Sukhatme VP 1995 Early growth response protein 1 (Egr-1): prototype of a zinc-finger family of transcription factors. Progress in Nucleic Acid Research and Molecular Biology 50 191-224.

Gutierrez LS, Eliza M, Niven-Fairchild T, Naftolin F \& Mor G 1999 The Fas/Fas-ligand system: a mechanism for immune evasion in human breast carcinomas. Breast Cancer Research and Treatment $\mathbf{5 4} 245-253$.

Hayashi S, Imai K, Suga K, Kurihara T, Higashi Y \& Nakachi K 1997 Two promoters in expression of estrogen receptor messenger RNA in human breast cancer. Carcinogenesis 18 459-464.

Holtz-Heppelmann CJ, Algeciras A, Badley AD \& Paya CV 1998 Transcriptional regulation of the human FasL promoter-enhancer region. Fournal of Biological Chemistry 273 4416-4423.

Ikeda K, Orimo A, Higashi Y, Muramatsu M \& Inoue S 2000 Efp as a primary estrogen-responsive gene in human breast cancer. FEBS Letters 472 9-13.

Inoue A, Yoshida N, Omoto Y, Oguchi S, Yamori T, Kiyama R \& Hayashi S 2002 Development of cDNA microarray for expression profiling of estrogen-responsive genes. Fournal of Molecular Endocrinology 29 175-192.

Jouvert P, Dietrich JB, Aunis D \& Zwiller J 2002 Differential rat brain expression of EGR proteins and of the transcriptional corepressor $\mathrm{NAB}$ in response to acute or chronic cocaine administration. Neuromolecular Medicine 1 137-151.

Kirsch KH, Korradi Y \& Johnson JP 1996 Mader: a novel nuclear protein over expressed in human melanomas. Oncogene 12 963-971.

Mages HW, Stamminger T, Rilke O, Bravo R \& Kroczek RA 1993 Expression of PILOT, a putative transcription factor, requires two signals and is cyclosporin A sensitive in T cells. International Immunology $\mathbf{5}$ 63-70.

Masiakowski P, Breathnach R, Bloch J, Gannon F, Krust A \& Chambon P 1982 Cloning of cDNA sequences of hormone-regulated genes from the MCF-7 human breast cancer cell line. Nucleic Acids Research 10 7895-7903.

Mercier G, Turque N \& Schumacher M 2001 Early activation of transcription factor expression in Schwann cells by progesterone. Brain Research. Molecular Brain Research 97 137-148.

Mittelstadt PR \& Ashwell JD 1998 Cyclosporin A-sensitive transcription factor Egr-3 regulates Fas ligand expression. Molecular and Cellular Biology 18 3744-3751.

O’Donovan KJ, Wilkens EP \& Baraban JM 1998 Sequential expression of Egr-1 and Egr-3 in hippocampal granule cells following electroconvulsive stimulation. Fournal of Neurochemistry $\mathbf{7 0}$ $1241-1248$

O'Donovan KJ, Tourtellotte WG, Millbrandt J \& Baraban JM 1999 The EGR family of transcription-regulatory factors: progress at the interface of molecular and systems neuroscience. Trends in Neurosciences 22 167-173.

Ozaki K, Nagata M, Suzuki M, Fujiwara T, Ueda K, Miyoshi Y, Takahashi E \& Nakamura Y 1998 Isolation and characterization of a novel human lung-specific gene homologous to lysosomal membrane glycoproteins 1 and 2: significantly increased expression in cancers of various tissues. Cancer Research $\mathbf{5 8}$ 3499-3503.

Pike MC, Spicer DV, Dahmoush L \& Press MF 1993 Estrogens, progesterones, normal breast cell proliferation, and breast cancer risk. Epidemiologic Reviews 15 17-35.
Prest SJ, May FE \& Westley BR 2002 The estrogen-regulated protein, TFF1, stimulates migration of human breast cancer cells. FASEB foumal 16 592-594.

Qu Z, Wolfraim LA, Svaren J, Ehrengruber MU, Davidson N \& Milbrandt J 1998 The transcriptional corepressor NAB2 inhibits NGF-induced differentiation of PG12 cells. Fournal of Cell Biology 142 1075-1082.

Rabinowich H, Reichert TE, Kashii Y, Gastman BR, Bell MC \& Whiteside TL 1998 Lymphocyte apoptosis induced by Fas ligand-expressing ovarian carcinoma cells. Implications for altered expression of $\mathrm{T}$ cell receptor in tumor-associated lymphocytes. fournal of Clinical Investigation 101 2579-2588.

Russo MW, Sevetson BR \& Milbrandt J 1995 Identification of NAB1, a repressor of NGFI-A- and Krox20-mediated transcription. PNAS 92 6873-6877.

Sevetson BR, Svaren J \& Milbrandt J 2000 A novel activation function for NAB proteins in EGR-dependent transcription of the luteinizing hormone beta gene. Fournal of Biological Chemistry 275 9749-9757.

Shoker BS, Jarvis C, Sibson DR, Walker C \& Sloane JP 1999 Oestrogen receptor expression in the normal and pre-cancerous breast. Fournal of Pathology 188 237-244.

Soulez M \& Parker MG 2001 Identification of novel oestrogen receptor target genes in human ZR75-1 breast cancer cells by expression profiling. Fournal of Molecular Endocrinology 27 259-274.

Stack G, Kumar V, Green S, Ponglikitmongkol M, Berry M, Rio MC, Nunez AM, Roberts M, Koehl C \& Bellocq P 1988 Structure and function of the pS2 gene and estrogen receptor in human breast cancer cells. Cancer Treatment and Research $\mathbf{4 0}$ $185-206$.

Suggs SV, Katzowitz JL, Tsai-Morris C \& Sukhatme VP 1990 cDNA sequence of the human cellular early growth response gene Egr-1. Nucleic Acids Research 254283.

Svaren J, Sevetson BR, Apel ED, Zimonjic DB, Popescu NC \& Milbrandt J 1996 NAB2, a corepressor of NGFI-A (Egr-1) and Krox20, is induced by proliferative and differentiative stimuli. Molecular and Cellular Biology 16 3545-3553.

Tourtellotte WG \& Milbrandt J 1998 Sensory ataxia and muscle spindle agenesis in mice lacking the transcription factor Egr3. Nature Genetics 20 87-91.

Tourtellotte WG, Keller-Peck C, Milbrandt J \& Kucera J 2001 The transcription factor Egr3 modulates sensory axon-myotube interactions during muscle spindle morphogenesis. Development of Biology 232 388-399.

Urano T, Saito T, Tsukui T, Fujita M, Hosoi T, Muramatsu M, Ouchi Y \& Inoue S 2002 Efp targets 14-13-3 sigma for proteolysis and promotes breast tumour growth. Nature $\mathbf{4 1 7}$ 871-875.

Wang D, Mayo MW \& Baldwin AS Jr 1997 Basic fibroblast growth factor transcriptional autoregulation requires EGR-1. Oncogene $\mathbf{1 4}$ 2291-2299.

Westley B \& Rochefort H 1980 A secreted glycoprotein induced by estrogen in human breast cancer cell lines. Cell 20 353-362.

Received 27 January 2004 Accepted 10 March 2004 